\title{
Joint optimal flood control operation of large scale mixed reservoirs
}

\author{
Gang Zha ${ }^{1,2}$, Jianzhong Zhou ${ }^{1,2, a}$,Lu Chen ${ }^{1,2}$, Quansen Wang ${ }^{1,2}$, Chengwei Lu $^{1,2}$,Xin Yang ${ }^{1,2}$, Ling Dai ${ }^{1,2}$ and Chao Zhou ${ }^{3}$ \\ ${ }^{1}$ School of Hydropower and Information Engineering, Huazhong University of Science and Technology, Wuhan 430074, PR China \\ ${ }^{2}$ Hubei Key Laboratory of Digital Valley Science and Technology, Huazhong University of Science and Technology, PR China \\ ${ }^{3}$ Changjiang Institute of Survey, Planning, Design and Research, 430010 Wuhan, China
}

\begin{abstract}
With the reservoir construction gradually completed, joint operation of reservoir groups is an important measure to realize reservoir flood control potential,but when the river basin is large, the flood channel routing and time-lag cannot be simplified, in addition, the curse of dimensionality is very difficult for model solving With the expansion of the number of reservoirs. These factors restrict the application of joint operation of large scale mixed reservoirs.In this study, The DP-POA cyclic iterative algorithm which is based on large scale system decomposed-coordinating method was proposed to solve the optimal problem considering the flood routing and time-lag.The upper Yangtze River is selected as a case study. 6 reservoirs, including the Three Gorges Reservoir(TGR)、Xiangjiaba Reservoir(XJB)、Xiluodu Reservoir (XLD)、 Pubugou Reservoir (PBG)、Goupitan Reservoir (GPT) and Tingzikou Reservoir (TZK)are taken into accounts.Compared with current operation of reservoirs independent,results demonstrate that the method can effectively reduce the maximum operating water level of TGR and flood diversion in the lower reaches of the TGR. Therefore, the safety of the flood control points along the river has been largely improved based on the proposed method.
\end{abstract}

\section{Introduction}

Flood disaster is one of the most damaging natural disasters, due to its high frequency and enormous destruction strength[1]. Reservoir is an effective engineering measure for flood control and disaster reduction. Optimization techniques for planning, design, and management of complex water resources systems have longstanding use in water resources engineering [2]. such as linear programming [3], dynamic programming (DP)[4], nonlinear programming [5], and folded dynamic programming (FDP) [6]. A variety of common operating rules have been derived for single-purpose reservoirs in series and in parallel[7]. Labadie[8] discusses the technological challenges and rewards of integrated optimization of reservoir systems.

Flood management reservoirs regulate inflows to reduce downstream flood damages[9]. These methods have been applied to small scale reservoir groups and achieved effective results. However, with the increase of the number of reservoirs and the increase of catchment area, some factors that can be ignored in the small reservoir groups become more and more influential and cannot be ignored. First, The time required for the model calculation increases rapidly with the increase of the number of reservoirs so that it is eventually unacceptable, for example, DP cannot be applied to joint flood control of more than four reservoirs because of the dimension disaster problem; Second, With the increase of river length, the phenomenon of flood peak attenuation and loss is more and more serious, and the propagation delay is also more and more long, so that these factors which can be ignored in small watershed area become very important; Third, There are hydraulic connections between series reservoirs, so that many methods that can be applied to parallel reservoirs without hydraulic connections are not suitable for series reservoirs; Last but not least, the increasing number of reservoirs and the complex hydraulic connections between reservoirs make it difficult to find feasible initial solutions, which have a great impact on the convergence of algorithms such as POA. These problems bring great challenges to the modeling and solving of the joint flood control operation of large-scale mixed reservoir group.

For the above problems, A DP-POA cyclic iterative algorithm based on large system decomposition and coordination theory is proposed. The upper Yangtze River is selected as a case study. 6 reservoirs, including the Three Gorges Reservoir(TGR) 、 Xiangjiaba Reservoir(XJB)、Xiluodu Reservoir (XLD)、Pubugou Reservoir (PBG)、Goupitan Reservoir (GPT) and Tingzikou Reservoir (TZK) are taken into accounts. Compared with current operation of reservoirs independent,results demonstrate that the method can effectively reduce the maximum operating water level of TGR and flood diversion in the lower reaches of the TGR. Therefore, the safety of the flood control points along the river has been largely improved based on the proposed method.

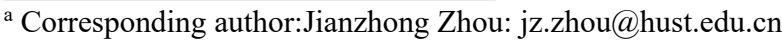




\section{Methodology}

As shown in Fig. 1, The algorithm includes the following steps : First, Simplify the series reservoirs into a virtual reservoir ; Second, establish joint flood control Operating model; Third, from upstream to downstream, from tributary to main stream, DP algorithm is used to calculate reservoir optimization one by one and obtain the initial solution of reservoir group joint operation ; Fourth, taking the DP algorithm as the initial solution, the POA algorithm considering phenomenon of flood peak attenuation and loss is used to solve the joint flood control model ;Fifth The calculation results of virtual reservoirs are decomposed into serial reservoirs.

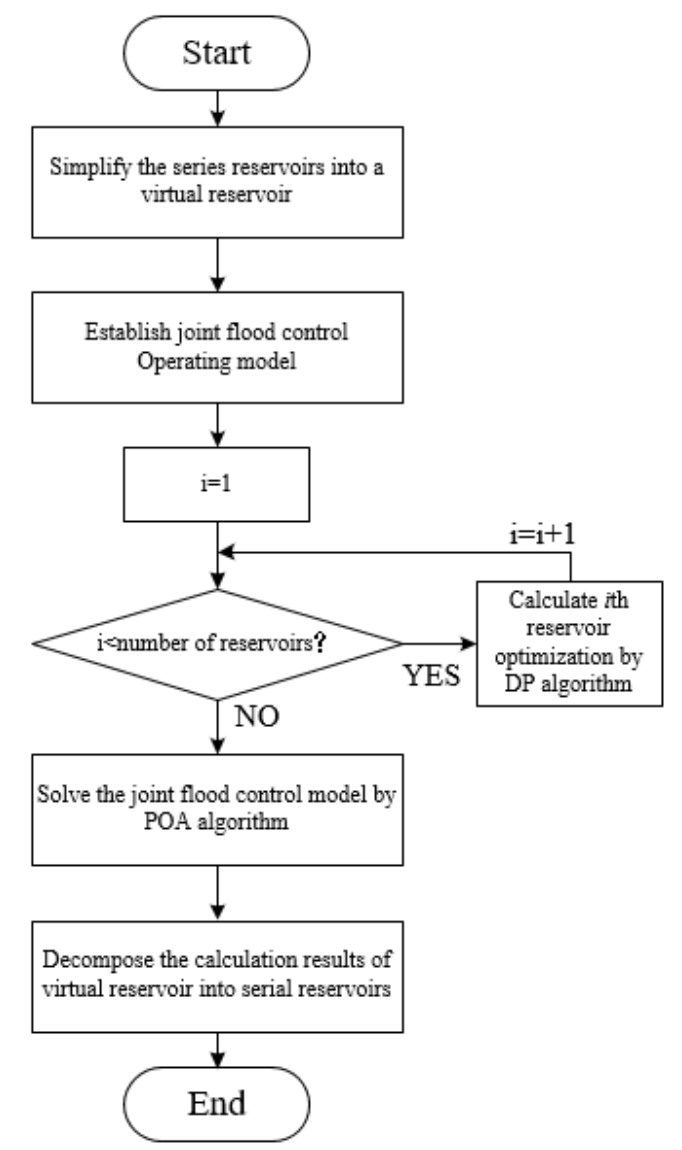

Figure 1. Algorithm flow chart

\subsection{Operating model}

Based on the flood control demand and the flood control capability of the basin, the integrated flood control model of reservoir group is established.

\subsubsection{Objective function}

The joint flood control operation of large-scale reservoir often involves multiple objectives.(1) the excess flood capacity of flood control points is the least;(2) the maximum adjusted flood level of the reservoir is lowest to reduce flood risk;(3) minimum sum of squares of flow at flood control points;(4) minimum sum of squares of outflow of reservoir. The above four objectives are combined to be one objective by using weight method, The final objective function is shown below:

$\min F=\min \left(\sum_{i=1}^{N}\left(a_{i} \frac{Z_{i}^{\max }-Z_{i}^{1}}{Z_{i}^{2}-Z_{i}^{1}}+\sum_{t=1}^{T} b_{i} Q_{t, i}^{2}\right)+\sum_{j=1}^{M} \sum_{t=1}^{T}\left(c_{j} Q_{t, j}^{2}+d_{j} Q_{t, j}^{e} \Delta t\right)\right)(1)$

where $F$ is Objective function value; $i$ is the number reservoir; $N$ is the total number of reservoir; $t$ is operating period number; $j$ is the number of flood control points; $M$ is the total number of flood control points; $Z_{i}^{\max }$ is maximum operate level of reservoir $i$; $Z_{i}^{1}$ is the allowable minimum water level of reservoir $i$; $Z_{i}^{2}$ is the allowable maximum water level of reservoir $i$; $a_{i}$ is the Weight coefficient of the maximum adjusted flood level of reservoir $i$; $Q_{t, \mathrm{i}}$ is the ohtflow of the reservoir $i$ at peroid $t ; b_{i}$ is the weight coefficient of the squared outflow of reservoir $i$; $Q_{t, j}$ is the ohtflow of the flood control point $i$ at peroid $t ;{ }^{c_{j}}$ is the weight coefficient of the squared outflow of flood control point $i ; Q_{t, j}^{e}$ is the value exceed the safe flow of the flood control point $i$ at peroid $t ; \Delta t$ is the length of operating period; ${ }^{d}{ }_{j}$ is the weight coefficient of the value exceed the safe flow of the flood control point $j$.

\subsubsection{Constraints}

(1) The lowest and the highest water level constraints:

$$
Z_{i, t}^{\min } \leq Z_{i, t} \leq Z_{i, t}^{\max }
$$

where $Z_{i, t}$ is the ith reservoir $i$ water level at period $t$; $Z_{i, t}^{\min }$ and $Z_{i, t}^{\max }$ are the ith reservoir allowable minimum and maximum water level at period $t$.

(2) The water balance constraint:

$$
V_{i, t}=V_{i, t-1}+\left(I_{i, t}-Q_{i, t}\right) \Delta t
$$

where $V_{i, t}$ and $V_{i, t-1}$ are the ith reservoir storage status at the beginning and the end of time period $t ; I_{i, t}$ and $Q_{i, t}$ are the ith reservoir inflow and outflow; $\Delta t$ is the peroid interval.

(3) The minimum outflow and the outflow capacity constraints:

$$
Q_{i, t}^{\min } \leq Q_{i, t} \leq Q_{i, t}^{\max }
$$

where $Q_{i, t}$ is the ith reservoir outflow at time $t ; Q_{i, t}^{\text {min }}$ and $Q_{i, t}^{\max }$ are the ith reservoir allowable minimum and maximum outflow at time $t$;

(4) The outflow amplitude constraint:

$$
\left|Q_{i, t}-Q_{i, t-1}\right| \leq \Delta Q_{i}
$$

where $\Delta Q_{i}$ is the ith reservoir allowable amplitude of outflow.

(5) Limits of discharge for downstream flood control point

$$
q_{j, t}=Q_{i, t}^{\prime}+\Delta q_{t} \leq q_{j}^{\max }
$$

where $q_{j, t}$ is the discharge at time $\mathrm{t}$ for the $\mathrm{jth}$ flood control point downstream. $Q_{i, t}^{\prime}$ is the discharge of the ith reservoir considering the flood routing at the jth flood 
control points, and $\Delta q_{t}$ is the inflow in the interval zones between the ith reservoir and the flood control point downstream. ${ }^{q_{j}^{\max }}$ is the allowed maximum discharge for the jth flood control point downstream.

\subsection{Flood channel routing}

This paper uses Muskingum method to calculate flood routing :

$$
O_{2}=C_{0} I_{2}+C_{1} I_{1}+C_{2} O_{1}
$$

where

$$
\left.\begin{array}{l}
C_{0}=\frac{0.5 \Delta t-K x}{K-K x+0.5 \Delta t} \\
C_{1}=\frac{0.5 \Delta t+K x}{K-K x+0.5 \Delta t} \\
C_{2}=\frac{K-K x-0.5 \Delta t}{K-K x+0.5 \Delta t}
\end{array}\right\}
$$

and

$$
C_{0}+C_{1}+C_{2}=1.0
$$

\section{Case study}

\subsection{Introduction of study area}

The upper Yangtze River is selected as a study. The basin topology diagram is shown in figure 2. The flood control system includes six reservoirs:Three Gorges Reservoir(TGR)、Xiangjiaba Reservoir(XJB)、Xiluodu Reservoir (XLD) 、 Pubugou Reservoir (PBG) 、 Goupitan Reservoir (GPT) and Tingzikou Reservoir (TZK). On the other hand, the system includes eight flood control points:Yinbin,Luzhou,Chongqing,Jingjiang,Chenglingji, Chengkun railway,Langzhong and Sinan.

Xiluodu reservoir and Xiangjiaba reservoir are located in the lower reaches of the jinsha river, Their aim is to ensure that Yibin,Luzhou and Chongqing meet flood control standards, and cooperate with the three gorges reservoir to reduce flood losses in the middle and lower reaches of the Yangtze river; Pubugou reservoir is located in Dadu River which is the tributary of the Minjiang River, Flood control aim of Pubugou reservoir is to ensure that Chengkun railway meet flood control standards and cooperate with other reservoirs to reduce flood losses of river basin; Tingzikou reservoir is located in Jialing River, Flood control aim of Pubugou reservoir is to ensure that Langzhou meet flood control standards and cooperate with other reservoirs to reduce flood losses of river basin; Goupitan reservoir is located in Wujiang River, Flood control aim of Goupitan reservoir is to ensure that Sinan meet flood control standards and cooperate with other reservoirs to reduce flood losses of river basin. The specific parameters of the reservoir are shown in table 1.

The flood control standardof flood control points is shown in table 2. The goal of reservoir group operation is shown below.

(1) Ensure the safety of the reservoirs, this target translates into a water level constraint;

(2) Ensure Yibin, Luzhou, Chengkun railway, Langzhong,sinan, and Chongqing meet flood control standards.In other word, When the flow is lower than the designed flow, the flow after regulation shall not exceed the safe flow;

(3) The jingjiang river does not divide flood when the peak flow below 100-year design flood;

(4) Minimize excess flooding in the Chenglingji area.

(5) Minimize the maximum flood operation level of the Three Gorges Reservoir;

(6) Minimize the the sum of squared outflow the reservoirs;

(7) Minimize the the sum of squared flow the flood control points.

\subsection{Results}

The method proposed is used to operate the 50-year design flood ,100-year design flood , 1000-year design flood,with selecting 1954, 1980, 1969, 1981, 1998and 2010 to be typical flood hydrograph. The results show that: 


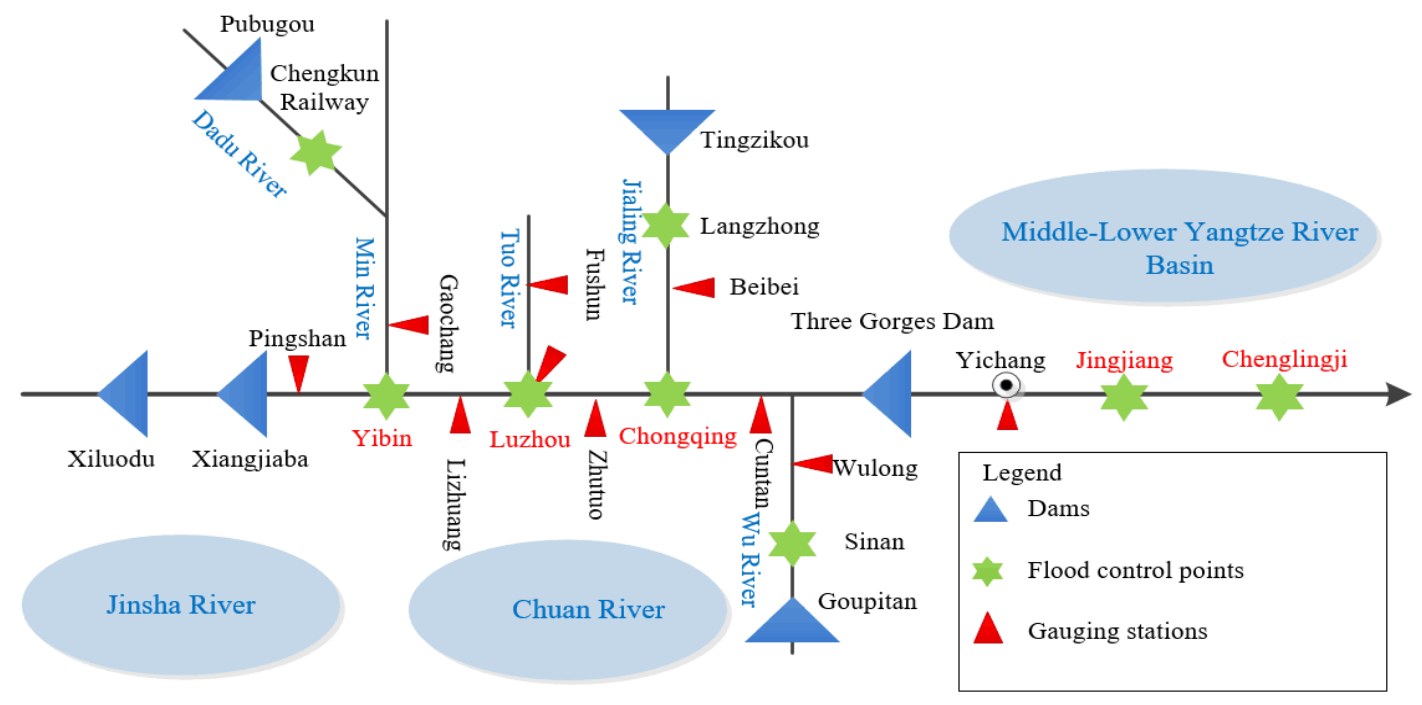

Figure 2. The basin topology diagram

Table 1 Characteristics of the Reservoirs

\begin{tabular}{|c|c|c|c|c|c|c|}
\hline Dams & $\begin{array}{c}\text { Drainage area } \\
\left(10^{4} \mathrm{~km}^{2}\right)\end{array}$ & $\begin{array}{c}\text { Normal water } \\
\text { level } \\
\text { (m) }\end{array}$ & $\begin{array}{l}\text { Flood control } \\
\text { Water level } \\
\text { (m) }\end{array}$ & $\begin{array}{c}\text { Dead water } \\
\text { level } \\
\text { (m) }\end{array}$ & $\begin{array}{l}\text { Reservoir } \\
\text { capability } \\
\text { (b.c.m.) }\end{array}$ & $\begin{array}{c}\text { Flood control } \\
\text { reservoir } \\
\text { capacity } \\
\text { (b.c.m.) }\end{array}$ \\
\hline XLD & 45.44 & 600 & 560 & 540 & 12.67 & 4.65 \\
\hline ХJB & 45.88 & 380 & 370 & 370 & 5.16 & 0.90 \\
\hline PBG & 6.85 & 850 & $836.2 / 841$ & 790 & 5.33 & $1.1 / 0.73$ \\
\hline TZK & 6.11 & 458 & 447 & 438 & 4.06 & 1.44 \\
\hline GPT & 4.33 & 630 & $626.24 / 628.12$ & 590 & 6.45 & $0.4 / 0.2$ \\
\hline TGD & 100 & 175 & 145 & 145 & 45.07 & 22.15 \\
\hline
\end{tabular}

Table 2 The flood control standard of the flood control points(years)

\begin{tabular}{ccccccc}
\hline Flood control point & Yibin & Luzhou & Chongqing & Jingjiang & Chenglingji & Chengkun Railwa \\
\hline Safety discharge & 50 & 50 & 100 & 100 & -- & 100 \\
\hline Table 3 Flood diversion volumes of Chenglingji flood control point $\left(* 10^{8} \mathrm{~m}^{3}\right)$ \\
\hline $\begin{array}{c}\text { Typical flood } \\
\text { hydrograph }\end{array}$ & $\begin{array}{c}\text { Return } \\
\text { periods } \\
\text { (years) }\end{array}$ & $\begin{array}{c}\text { Without } \\
\text { operation }\end{array}$ & $\begin{array}{c}\text { Regular } \\
\text { operation }\end{array}$ & $\begin{array}{c}\text { Cascade } \\
\text { optimal } \\
\text { operation }\end{array}$ \\
\hline \multirow{5}{*}{1954} & 50 & 265.97 & 21.272 & 0 \\
& 100 & 340.97 & 122.232 & 84.53 \\
& 1000 & 442.94 & 432.536 & 412.48 \\
\hline \multirow{2}{*}{1980} & 50 & 386.76 & 71.248 & 46 \\
& 100 & 511.85 & 326.808 & 309.2 \\
& 1000 & 876.38 & 830.088 & 819.1 \\
\hline \multirow{2}{*}{1981} & 50 & 389.82 & 10.456 & 0 \\
& 100 & 470.45 & 98.68 & 84.3 \\
& 1000 & 683.2 & 564.216 & 557.1 \\
\hline \multirow{2}{*}{1998} & 50 & 406.11 & 84.72 & 66.45 \\
& 100 & 517.53 & 224.448 & 210.77 \\
& 1000 & 670.54 & 593.8 & 575.17 \\
\hline & 50 & 365.2 & 9.62 & 0.00 \\
& 100 & 450.7 & 182.3 & 132.84 \\
& 500 & 639.3 & 610.42 & 597.43 \\
\hline
\end{tabular}


(1) The maximum operating water level of all reservoirs is below the safe water level;

(2)Yibin, Luzhou, Chengkun railway, Langzhong,sinan, Jinjiang and Chongqing have achieved flood control standards;

(3) Compare to existing methods, The method proposed in this paper greatly reduces the excess flood volume in the chenglingji area;

(4) It significantly lowered the maximum operating water level of the three gorges reservoir,this helps to reduce flood risk.

\section{CONCLUSIONS}

This paper focuses on the joint flood control operation of large-scale mixed reservoir group, The DP-POA cyclic iterative algorithm which is based on large scale system decomposed-coordinating method was proposed.,and this method was applied to the joint flood control of reservoirs on the upper reaches of the Yangtze river. Compared with current operation of reservoirs independent,results demonstrate that the method can effectively reduce the maximum operating water level of TGR and flood diversion in the lower reaches of the TGR. Therefore, the safety of the flood control points along the river has been largely improved based on the proposed method.

\section{ACKNOWLEDGES}

This work is supported by the National Natural Science Foundation Key Project of China (No. 91547208), the National Natural Science Foundation of China (No. 51579107), the National Key R\&D Program of China (No. 2016YFC0402210), the National Natural Science Foundation of China (No.91647114), the project from CISPDR with the title of "Impact of flood control multireservoir co-operation in the upper Yangtze River Basin on the Three Gorges Reservoir and its corresponding risk analysis" and the Fundamental Research Funds for the Central Universities (No. 2017KFYXJJ209).

\section{REFERENCES}

1. H. Qin,J.Zhou,Y.Lu,et al, Water Resour Manage (2010) 24:2611-2632

2. Yeh, W. W.-G. (1985). Water Resour. Res., 21(12), 1797-1818

3. Windsor JS (1973). Water Resour Res 9:12191226

4. Schultz GA, Plate EJ (1976).J Hydrol 28:245-264

5. Unver OI, Mays LW (1990). Water Resour Manag $4: 20-45$

6. Nagesh Kumar D, Baliarsingh F (2003). Water Resour Manag 17:337-353

7. Lund, J. R., and Guzman, J. (1999). Water Resour. Plann. Manage. 125:3(143), 143-153.

8. Labadie, J. W. (2004). Water Resour. Plann. Manage.130:2(93), 93-111.
9. Yazdi, J., and Neyshabouri, S. A. A. S. (2012). Natural Hazards,63(2), 629-646. 